\title{
A methodology to institutionalise user experience in provincial government
}

\author{
Marco C. Pretorius, André P. Calitz \\ Department of Computing Sciences, Nelson Mandela Metropolitan University, South Africa
}

\begin{abstract}
Problems experienced with website usability can prevent users from accessing and adopting technology, such as e-Government. At present, a number of guidelines exist for e-Government website user experience (UX) design; however, the effectiveness of the implementation of these guidelines depends on the expertise of the website development team and on an organisation's understanding of UX. Despite the highlighted importance of UX, guidelines are rarely applied in South African e-Government website designs. UX guidelines cannot be implemented if there is a lack of executive support, trained staff, budget and user-centred design processes. The goal of this research is to propose and evaluate a methodology (called the "Institutionalise UX in Government (IUXG) methodology") to institutionalise UX in South African Provincial Governments (SAPGs). The Western Cape Government in South Africa was used as a case study to evaluate the proposed IUXG methodology. The results show that the IUXG methodology can assist SAPGs to establish UX as standard practice and improve the UX maturity levels.
\end{abstract}

KEYWORDS: User experience, usability, e-government, provincial government, user experience maturity

CATEGORIES:

Human-centred computing: Human-computer interaction (HCI)

Applied computing: e-government

\section{INTRODUCTION}

The number of e-Government users worldwide is growing significantly and their expectations for improved services are continuously increasing [1]. The African e-Government sector has shown substantial growth in recent years [2]. The Internet has become a crucial tool to disseminate information to citizens. However, poorly designed websites can drive a wedge between a government and its citizens 3. The importance of usability evaluation for government websites, in particular, has increased over the past years 4]. Research has shown that the poor usability of government websites and the lack of user-centred design (UCD) methodologies are problematic in several countries [5].

African e-Government websites, including South African websites, generally have high failure rates and usability problems 6]. Designing a user-friendly and functional provincial government website is a challenging task [7]. A website that is difficult to navigate and does not meet the user's needs and requirements increases the frustration of the user and the difficulty and complexity of the successful completion of tasks.

Internationally, countries such as the United States and the United Kingdom have shown support for usability in e-Government [8] and a number of guidelines and

Email: Marco C. Pretorius marco.pretorius@gmail.com André P. Calitz andre.calitz@nmmu.ac.za principles exist for e-Government website design [2, 9]. However, these principles and guidelines are generally not being applied by South African Provincial Government (SAPG) website designers [10. The application of UCD is crucial to ensure an effective user experience (UX). UX guidelines cannot be implemented with insufficient executive support, inadequately trained staff, limited budget, or inefficient use of UX methodologies and UCD processes.

The challenge at present in the UX design field is the institutionalisation of UX 11. The definition of 'institutionalisation' used in this study is as follows:

Establish (something, typically a practice or activity) as a convention or norm in an organisation or culture. [12]

Institutionalising UX in an enterprise demands the establishment of routine practice, the use of best practices, and the supply of tools, methods and resources. Inclusion of internal and external personnel is essential [13.

The problem researched in this study is based on the realisation that SAPG websites do not implement UX guidelines [10, despite the highlighted importance of doing so. The importance of e-Government in South Africa has been communicated by the South African Government. However, there are no clear mandates on UX and how to achieve this in South African National, Provincial or Local Government websites. The research questions addressed in this study are: 
- How can a methodology be proposed and evaluated to institutionalise UX in a South African Provincial Government?

- How will the implementation of the UX methodology increase the UX maturity of a South African Provincial Government?

The motivation and purpose of this research is to propose a methodology that will support the institutionalisation of UX in a SAPG, named the "Institutionalise UX in Government (IUXG) methodology". The usefulness and usability of the methodology will be determined by applying the methodology in a case study focusing on the Western Cape Government (WCG). This research makes a key contribution in addressing the current lack of UX practices in SAPGs. South African and Provincial Governments abroad, can use the proposed IUXG methodology to institutionalise UX as it will assist Provincial Government (PG) officials to develop increased usability and UX maturity levels. The advantage of the IUXG methodology is that it provides PG officials with a step-by-step method to institutionalise UX in a Provincial Government by following the six phases of the IUXG methodology namely: startup, setup, organisation, method, standards and long-term. The IUXG methodology will assist SAPGs to establish UX practice as standard practice. The IUXG methodology will further assist Provincial Governments with resources, methods and tools to enable them to implement UX guidelines, which will result in an improved, more usable and more user-centric e-Government website.

This article is organised as follows: A background of the study is provided by discussing UX in eGovernment as well as the WCG, the case study for this research. The research method of this study is discussed, followed by the recommended IUXG methodology. The case study results of each step of the methodology are provided. Finally, the contributions of this study are discussed followed by the conclusions and future research.

\section{BACKGROUND}

The background of this study is explained by providing an introduction to UX in e-Government and specifically in South Africa. This is followed by a background of the WCG, the case study for this research.

\subsection{User experience in e-Government}

The Internet provides an opportunity for governments to offer services to their citizens using websites [14. Government websites potentially offer information and benefits to citizens and governments, but the benefits cannot be realised if websites are not usable [14, accessible, findable, credible and useful. Problems with website accessibility and usability prevent people from accessing and eventually adopting technology such as the Internet and e-Government [15]. A lack of usability can be considered as one of the major problems causing the lack of usage of governmental websites [4].
Usability is defined as:

- how quickly can people learn to use a system,

- how efficient they are whilst using it,

- how memorable it is,

- how error-prone it is, and

- how much users like using it [16].

UX is defined as all aspects of the user's experience when interacting with the system that produces the user's perceptions [17]. This research study will refer to UX, where it is implied that usability is a sub-set of UX.

Increased perception of the usefulness and ease of use of e-Government websites among citizens directly enhances the level of citizens' continued intention to use e-Government websites [5]. It can be argued that, unless usability at a detailed level in e-Government website design is addressed, e-Government still retains the challenging target of how best to interact with users 18. Research further indicates the importance of usability to e-Government [19], [18, 20]. Although international UX guidelines on webpage development exist, these guidelines are not often followed [14]. Currently, the problems are the lack of understanding and buy-in of UX at various levels of government and individual authorities do not necessarily have the experience or infrastructure to develop websites that are usable and that can be continuously maintained as content changes [8].

In the United States the importance of UX in government websites has grown and is considered best practice [21]. The US has official UX websites ${ }^{1}$ that are sources for government web designers to learn how to make websites more usable, useful and accessible. In January 2012, the United Kingdom government launched a new website, http://www.gov.uk, to replace the http://www.direct.gov.uk website. The website states: "We're constantly working to make GOV.UK as accessible and usable as possible" [22].

\subsection{User experience in the South African Government}

Interacting with South African Government websites can be a frustrating experience [23]. Citizen-togovernment interactions are mired with complexity [24. Korsten and Bothma [9] compiled a South African Government website audit where the findings indicated that there was a need for government websites to improve considerably with regard to content, information architecture, navigation, search and design. The South African Government did not have any direct policies or guidelines relating to Web design when initial government websites were developed 9]. Continuous scientific usability engineering practices were not followed during the development of South African Government websites [9]. A recent study showed that SAPGs do not have UX strategies in place and do not focus on UX in the development lifecycle [10]. Furthermore, leadership, project fragmentation and stakeholder engagement are

\footnotetext{
${ }^{1}$ http://www.usability.gov and http://www.howto.gov
} 
some of the main factors that affect the implementation of e-Government projects at a provincial level in the South African context 24].

Yeratziotis 2] provides guidelines and recommendations that will improve the South African eGovernment website2. UX guidelines for e-Government websites, such as the study by Yeratziotis [2] exist; however, there are limited signs that SAPGs have applied these guidelines on existing sites.

A survey was conducted amongst stakeholders 10] in each of the nine Provinces in South Africa. The goal of the survey was to determine the UX maturity of each of the Provinces. UX maturity models were identified to determine the maturity level. UX maturity models allow the assessment of the degree of capability reached by a SAPG and its ability to perform human-centred design activities. The identified maturity models were those of Schaffer [13, Nielsen 25] and Feijo 26.

The results indicated that UX has not reached the required maturity levels in SAPGs. The majority of SAPGs were rated low in the UX maturity models. The SAPG with the highest rating in each model had at least three levels to progress before reaching the highest level of each maturity model. These results were validated and supported by a list of UX generic questions: six SAPGs did not recognise UX as a valued skill; only four SAPGs had UX employees; no SAPGs had UX strategies in place and only one SAPG had UX forming part of its development lifecycle.

HFI's 2009 UX Maturity Survey [27] indicates that stable, visible, internal UX groups with executive support have become significantly more prevalent since Schaffer 13. outlined the elements of a mature UX practice. However, the survey results showed that this statement does not hold true for SAPGs. UX is presently not at a mature stage. It is impossible to take an organisation from UX indifference to UX maturity 28].

In the South African Government environment, there are limited signs of citizen-centric website development. UX is not presently a best practice or a standard in South African National, Provincial or Local Government.

\subsection{The Western Cape Government, South Africa: Case study}

The primary author of this research is currently based in Cape Town in the Western Cape Province in South Africa. The author is the User Experience Manager in the WCG. The role of the User Experience Manager is to manage UX in a component of the WCG: e-Government for Citizens (e-G4C). At the time of employment, UX was not institutionalised in the WCG. As the author was and presently is directly involved in institutionalising UX in the WCG, the WCG was selected as the case study for this research.

The WCG is the Provincial Government that governs the Western Cape in South Africa. The WCG

\footnotetext{
${ }^{2}$ http://www.gov.za/
}

has a more advanced e-Government programme compared to other provinces in South Africa 24, 29]; however the programme lacks adequate resources for successful planning and implementation of individual e-Government projects 29. The WCG is currently re-writing its e-Government strategy. A new draft version was made available for public comment in October 2012 [30].

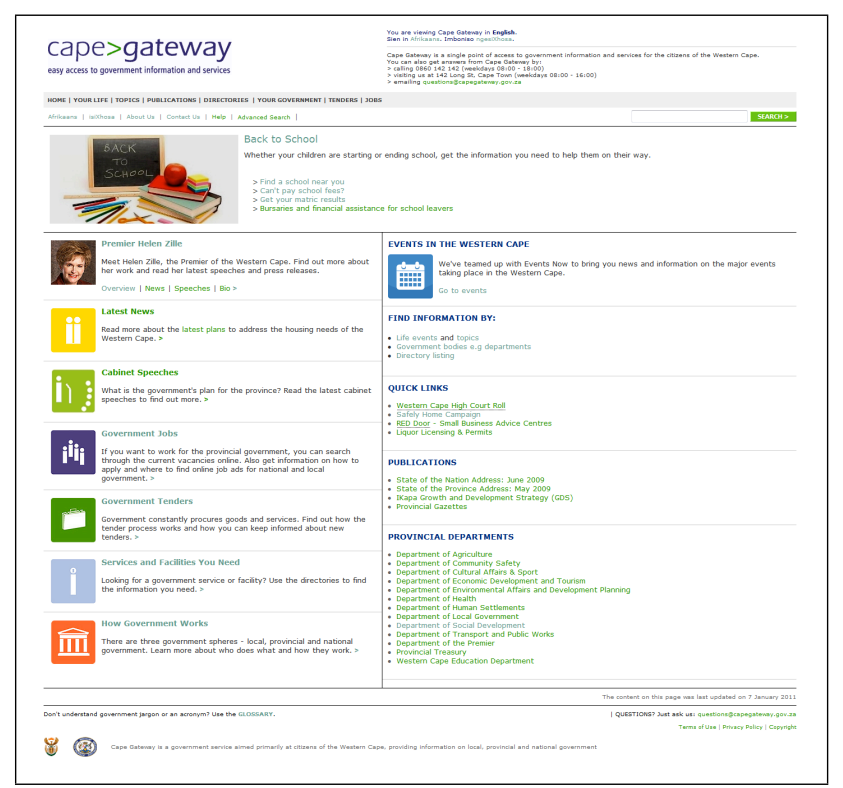

Figure 1: Western Cape Government website before this study (January 2010)

The WCG supported the presidential drive for eGovernment by launching an Internet portal in 2004 . The Western Cape Government website is the single point of access to provincial government information and services for citizens of the Western Cape 31. The website is managed by e-G4C and was used as the focus area in the WCG during this study. Figure 1 illustrates the WCG home page at the beginning of this research study (January 2010). The WCG website was a leader of government websites, but has become less effective due to a lack of ownership, funding, governance processes, long-term e-service strategy, cross agency collaboration, as well as high staff turnover [29].

\section{RESEARCH METHODOLOGY}

In order to answer the research questions of this study, data were collected by means of a literature study, surveys and a case study. The literature study collected data about usability and UX maturity models, institutionalising UX in an organisation, e-Government websites locally and internationally, and UX in the WCG.

A single case study was conducted using the WCG as the SAPG. A case study is a strategy for doing research which involves an empirical investigation of a particular contemporary phenomenon within its real life context by using multiple sources of evidence 32 . Compared to other methods, the strength of the case 
study method is its ability to examine, in-depth, a case within its real-life context 33. The case study method helps to make direct observations and collect data in natural settings, compared to relying on derived data. The case study was used to evaluate the proposed IUXG methodology and the Western Cape Government formed the basis of the case study.

Case studies can provide important feedback when a study is in the initial stages of understanding the problem and the merits of possible solutions [34. The institutionalisation of UX in Provincial Governments is in the initial stages in South Africa [10]. The use of a case study can provide meaningful feedback to SAPGs and other emerging market governments. Case studies use analytical rather than statistical generalisation: that is, they develop a theory which can help researchers to understand similar cases or situations 35. A case study strategy could be used successfully in this study to answer the research questions.

There are four characteristics of case studies [36], namely:

In-depth investigation of a small number of cases. Case studies use an in-depth, broad examination of a small number of cases in order to address a broad range of concerns. The WCG is used as the case study to examine the phases and steps of the proposed IUXG methodology;

Examination in context. Case studies are useful when detailed knowledge of any particular case is required. The WCG is the SAPG context of the study;

Multiple data sources. Case studies often rely on multiple data sources and collection techniques to act as sources of verifying evidence which can increase confidence in the data. The results of the case study included input from WCG officials and contract workers, surveys as well as results from WCG projects;

Emphasis on qualitative data analysis. The results of this research study are of a qualitative nature.

A case study is therefore particularly suited as the research strategy for this study. The risks and constraints of a case study are identified and resolved as follow 36, 37]:

The risk of losing focus. A single case study was explored, namely the WCG. The WCG has appointed appropriate staff with a mandate to manage the WCG e-Government website. This assisted in keeping focus on the research study;

Generalisability of results. South Africa has nine Provincial Governments each with a mandate to have a Provincial Government website; therefore, the results of the research will be generalisable for use to all SAPGs;

Subjectivity. In order to avoid subjectivity, official procedures and professional protocols were followed and results were documented to obtain the case study results of this study. Additionally, WCG officials were included as participants in the surveys and consulted regarding the case study results;
Time-consuming. This constraint consequently allowed for only a single case study to be explored.

Single case studies have been successfully used in human-computer interaction [36] and can provide analytic rather than statistical generalisations. A single case study approach was therefore used in this research and the case study selected was the WCG, a SAPG.

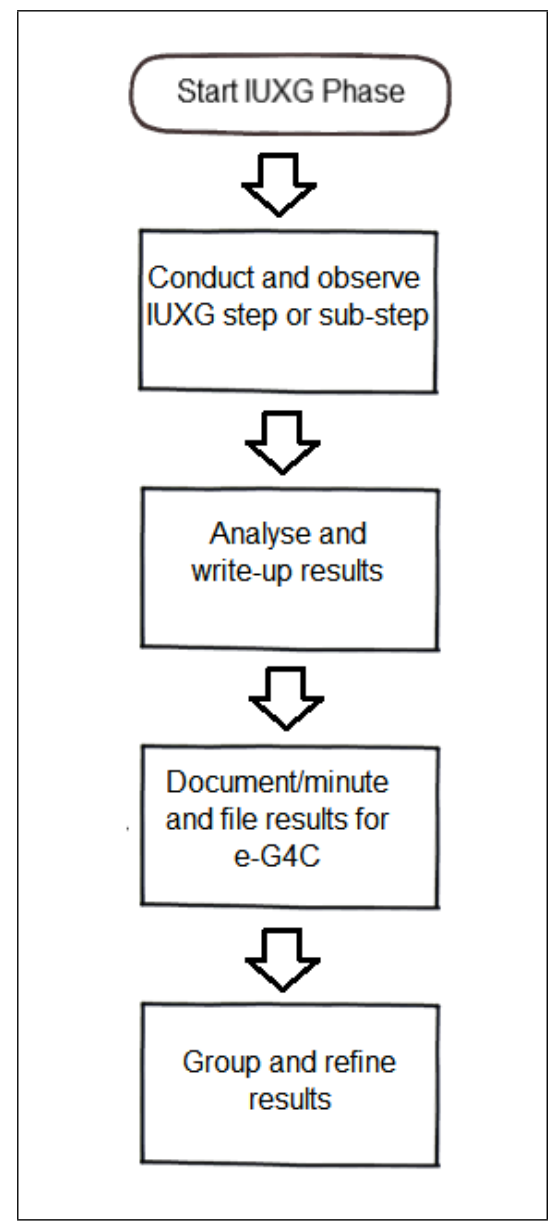

Figure 2: Case study data collection

The data collected in the case study were of a qualitative nature. Figure 2 illustrates the case study data collection process. The data were collected by following the specific phases and steps of the IUXG (discussed in the next section) in the e-G4C component. Official WCG procedures and professional protocols were adhered to in this study. The results were analysed, documented and filed as e-G4C official documents or minutes. The period of data collection was from July 2010 to November 2012. Several WCG website projects were conducted in this period. The results and lessons learnt from these projects were formally documented and analysed.

Research strategies are not mutually exclusive 32 and could incorporate a survey strategy as part of a case study. Three surveys were used during this research to determine the UX maturity level of SAPGs, as well as that of the WCG [10, 38.

The first survey demonstrated the need for the study by demonstrating the UX maturity in SAPGs. The survey was completed by participants who are 
direct stakeholders of SAPG e-Government websites (such as Directors, Web Content Managers and Web Managers) in each SAPG. Surveys were e-mailed to participants from the nine SAPGs. The results indicated that UX is not yet mature in SAPGs 10.

The second and third surveys were administered to WCG e-Government website officials before and after the implementation of the IUXG methodology. The surveys measured the UX maturity level of the WCG in the component, e-Government for Citizens (e$\mathrm{G} 4 \mathrm{C}$ ), responsible for the WCG e-Government website. One-on-one interviews were conducted with WCG officials as the method to administer the second and third surveys. In-person surveys are structured to permit an interviewer to solicit information directly from a respondent in personal interviews [39]. The survey is explained to participants and they have the opportunity to ask questions as required. The interviewer can probe for more detail, explain unclear questions and use visual aids, such as a print-out of the WCG e-Government website 39 .

The data analysis of each survey was done by grouping results into different categories. The categories of the UX maturity models as well as the IUXG methodology were used. Patterns and relationships were identified in the data in order to reach conclusions. The analysis was done in Microsoft Excel. The results was qualitatively and thematically analysed. The recommended IUXG methodology and case study results are discussed next. The second and third survey results are described in Phase $\mathrm{A}$ and Phase $\mathrm{F}$ of the methodology results, where measuring the UX maturity is required at the start and at the end of the methodology. The third survey illustrated that the UX maturity of the WCG increased after the implementation of the IUXG methodology and is discussed in Section 5 .

The sub-steps of the proposed IUXG methodology include, for example, focus groups and usability testing. These sub-steps are not the focus of the research paper.

Potential bias due to the author's close involvement in this research is addressed in Section 8.

\section{THE RECOMMENDED IUXG METHODOL- OGY AND RESULTS}

Methodologies to institutionalise UX exist [13] 21] 40] 41] 42. However, these UX methodologies are not aimed specifically at Provincial Governments. The objective of this research study was to propose and evaluate a methodology to institutionalise UX in SAPGs. The initial, proposed IUXG methodology was designed from five UX methodologies found in literature [13 21] 40, 41] 42, as well as best practices discussed in literature. The UX methodologies and best practices were grouped into a matrix where common themes, phases, steps and sub-steps were identified.

The IUXG methodology was updated, based on the results of a survey (the first) to SAPGs [10], a survey to WCG employees 38 (the second), as well as literature from the WCG. The IUXG methodology was updated a final time, based on the case study results and on a confirmation survey (the third) with WCG employees after the implementation of the case study.

The IUXG methodology (Figure 3) has the following six main phases:

- Phase A: Startup: start the UX initiative;

- Phase B: Setup: establish the infrastructure;

- Phase C: Organisation: develop the UX team;

- Phase D: Methodology: the required steps for conducting a UX project;

- Phase E: Standards: minimise rework and enforce consistency;

- Phase F: Long-term: long-term considerations in order to keep UX institutionalised in government.

The results of each of the main phases of the IUXG methodology (Figure 1) are discussed in this section. The IUXG methodology process is explained in terms of phases, steps and sub-steps. Using the example: "Phase A: Startup: Measure UX maturity level: Select a maturity model":

'Phase A: Startup'. The main components (Phase A, Phase B, etc.) are referred to as 'phases'.

'Measure UX maturity level'. Components at this level are referred to as 'steps'.

'Select a maturity model'. Components at this level are referred to as 'sub-steps'.

The phases and steps are discussed in this research. The full methodology, including sub-steps, is available from www.uxstrategy.co.za and Pretorius [38. This section will discuss the summarised results of the case study. The detailed results of the case study are available from Pretorius 38.

\subsection{Phase A: startup}

The focus of the startup phase is to highlight UX in order to start a UX initiative. The steps for Phase A include:

- A1. Measure UX maturity level;

- A2. Measure usability of current site;

- A3. Initialise a wake-up call;

- A4. Acquire an executive champion;

- A5. Procure a UX consultant;

- A6. Understand the company culture;

- A7. Obtain buy-in.

The UX maturity level of the WCG was measured (A1). This step required the selection of UX maturity models. The identified maturity models were those of Schaffer [13, Nielsen 25] and Feijo [26]. The measured UX maturity level for the WCG before this study was: Schaffer, stage 4, dedicated usability budget; Nielsen, level 2, piecemeal usability and Feijo, level 1, interested 38. These results were gathered from the second survey with WCG employees as the participants.

Focus groups were conducted to obtain an early measurement of usability of the WCG website (A2). This was the first time focus groups were used in e-G4C [43. The following groups participated in the focus groups:

- e-G4C staff, 


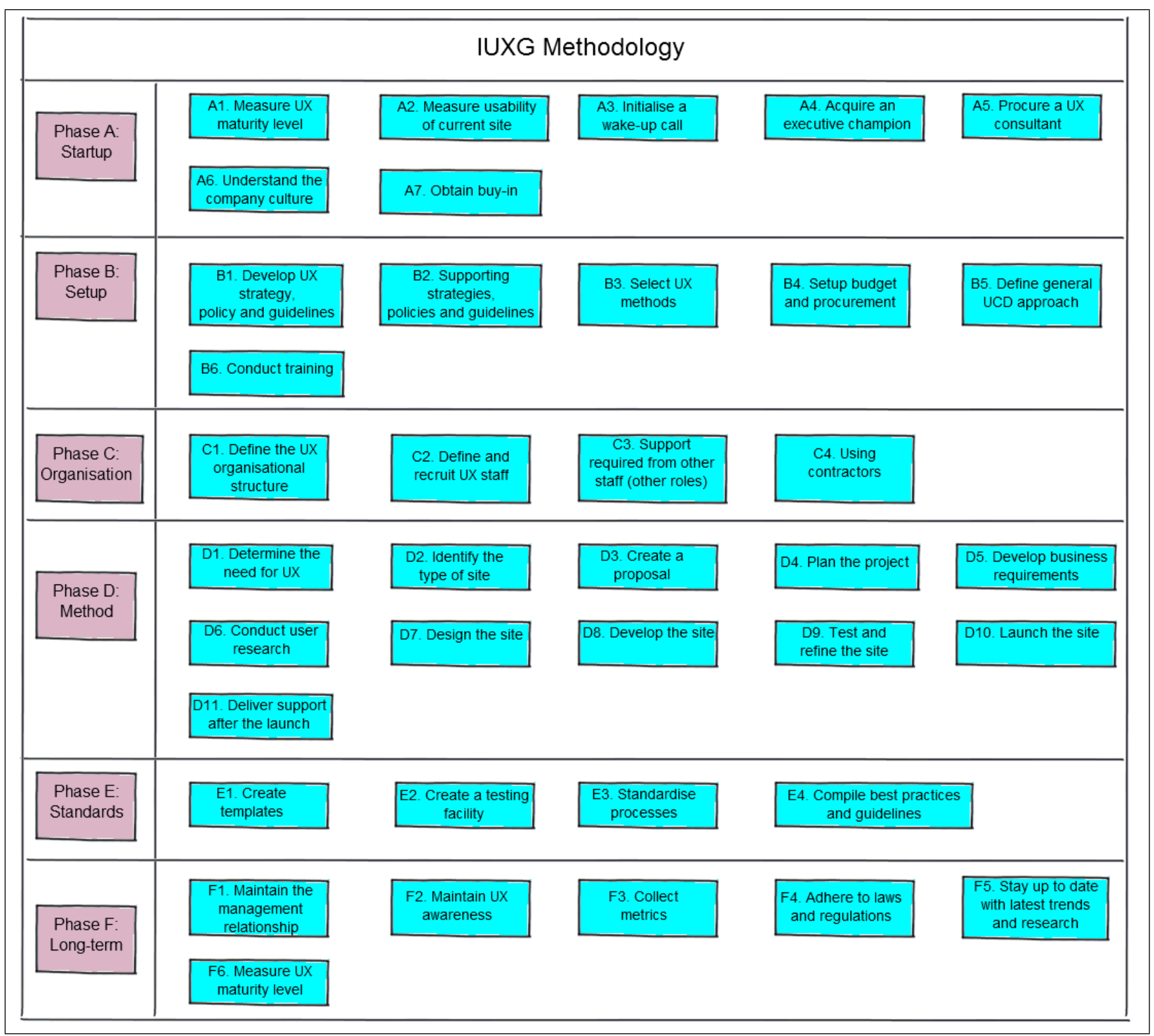

Figure 3: IUXG methodology

- WCG call centre staff,

- WCG contact centre staff,

- RED Door Advice Centre staf 3 .

- RED Door Advice Centre clients,

- Heads of Communications of WCG departments,

- citizens of the Western Cape.

The focus groups proved to be a success as findings resulted in recommendations to enhance and improve the current website 43 . Improvements to the website included: a top story carousel (slider) for the home page to have more frequent and new news items; mega drop-down menus to improve navigation; senseless icons were replaced with photos with meaning; department and ministry stakeholder information was moved above the fold of the page and displayed in a clearer fashion and several elements were renamed to be more comprehensible 43 .

\footnotetext{
${ }^{3}$ The Red Door Advice Centre provides administrative support to SMMEs in the Western Cape.
}

These results, as well as the UX maturity, were presented to management and contributed to the admonition (described as a "wake-up call" in the methodology) for the WCG (A3).

The Director of e-G4C was identified as the executive champion (A4). The executive champion assisted the cause of UX by:

- raising awareness of a UCD approach with the senior management team,

- requesting budget to resource UX projects with skilled professionals,

- promoting UX success stories and supporting organisational change to help institutionalise UX.

The primary author of this study was the UX consultant procured (A5).

The IUXG methodology recommended the investigation of the SAPG's history, purpose, hierarchy and logistics, in order to understand the organisational culture (A6). These elements were investigated by means of a survey with WCG officials (second survey). 
The history section, for example, provided information on previous challenges that WCG officials faced with usability and the WCG website.

Organisation and staff buy-in are required to truly institutionalise UX into an organisation and to ensure that it is not an afterthought (A7). The goal of this step was to change the mindset of management from considering UX as an extra step, to understanding the return on investment. The WCG achieved this by showing success stories and improvements by means of accounts of success and by presentations. Several presentations were delivered to advocate the concepts of UX in e-G4C and the WCG. Key presentations included:

e-G4C management and staff: UX concepts, usability testing videos, UX methods, wireframes and designs of website projects;

Senior IT management: presentations listed in the previous bullet, WCG UX maturity results, UX considerations for the WCG SDLC, usability study results;

Developers: UX concepts and usability testing, UCD;

National Department of Government Communication and Information Systems (GCIS): the concepts of UX and usability testing were presented in order to create UX awareness nationally;

Conferences and seminars: presenting UX topics at local and international conferences and seminars helped senior management to take note of the impact of UX.

Presentations were also delivered to WCG Departments. Phase A, startup, successfully initiated the UX initiative in the WCG.

\subsection{Phase B: setup}

The focus of the setup phase is to establish the infrastructure required to conduct efficient and professional UX work. The steps for Phase B include:

- B1. Develop UX strategy, policy and guidelines;

- B2. Supporting strategies, policies and guidelines;

- B3. Select UX methods;

- B4. Setup budget and procurement;

- B5. Define general UCD process;

- B6. Conduct training.

During 2012, a first draft document of official WCG UX policy, strategy and guidelines was released [44. The goal of this document was to provide a list of usability, design and UX guidelines to be applied to WCG websites and systems (B1). The policy states that all WCG websites and systems would have to follow the official UX guidelines. Policy and strategy for the UX team in e-G4C were provided additionally 44. The services that the UX team in e-G4C offered were described and descriptions were given how to conduct these services.

The UX team has to be supported by strategies, policies and guidelines from other components (such as content and technology) of the website development process (B2). Such supporting documentation includes: content, branding, training, social media, eGovernment, website, mobile and development strategies, policies and guidelines.

UX methods needed to be selected (B3) to improve the WCG e-Government website. The selected UX methods included: user research (focus groups, surveys), designing a website or system (wireframes and templates, Web design) and usability testing of a website or system (heuristic evaluations, usability laboratory testing). A dedicated UX budget and understanding of procurement methods are required (B4) and were set up to conduct UX methods:

- to recruit UX contractors,

- to build a testing facility,

- to procure UX software and hardware,

- to recruit usability testing participants,

- to provide incentives to usability testing participants, and

- to provide training.

A UCD process needs to be followed that specifies how the UX methods are included in the system's lifecycle process (B5). An approach was taken to include wireframing, Web design and heuristic evaluations at first and to gradually incorporate the other identified UX methods. The Systems Development Lifecycle (SDLC) was developed in consultation with the e-G4C stakeholders 45].

Training is required both to educate staff members about the importance of UX and to develop staff members who conduct interface design work (B6). Staff members were educated about the importance of the process of usability through presentations of UX topics. In addition, staff members, conducting interface design work, were sent on Human Factors International short courses offering international UX certification.

The setup phase (B) of the IUXG methodology established the infrastructure required to conduct efficient and professional UX work.

\subsection{Phase C: organisation}

The focus of the organisation phase is to develop a UX team. The steps for Phase $\mathrm{C}$ include:

- C1. Define the UX organisational structure;

- C2. Define and recruit UX staff;

- C3. Support required from other staff;

- C4. Using contractors.

The UX team was established as a centralised UX structure (C1): all UX staff members are in a single team and are assigned temporarily to help on specific projects as required. The UX team developed from one staff member in 2010 to five staff members in 2012. The staff members included the User Experience Manager, Web Designer, Information Architect, Business Analyst and User Researcher (C2). The team developed to nine members in 2014.

Support is required from other staff, not in the UX team, including: content, technology and other roles required from the website supporting staff (available 
from Pretorius [38). Content ownership by stakeholders and the procurement of technology resources both proved to be an on-going challenge for the WCG.

The IUXG methodology recommended the following steps when contractors are used (C4): write a statement of work; work collaboratively and transfer the skill to the in-house team. These steps were implemented successfully when contractors were used.

Phase $\mathrm{C}$ of the IUXG methodology assisted to develop the UX team.

\subsection{Phase D: method}

The focus of the method phase is to demonstrate what steps are required when conducting a UX project. The steps for Phase D include:

- D1. Determine the need for UX;

- D2. Identify the type of site;

- D3. Create a proposal;

- D4. Plan the project;

- D5. Develop business requirements;

- D6. Conduct user research;

- D7. Design the site;

- D8. Develop the site;

- D9. Test and refine the site;

- D10. Launch the site;

- D11. Deliver support after the launch.

The need for UX can be determined (D1) by asking the following questions:

- What is the importance of the project?

- How important is UX to the project?

- Can the project be used to measure the before and after benefits of UX?

- Does the project manager support UX?

- Is there time to revise the design?

These questions were incorporated into an e-G4C project brief (D3) and into the project planning phases. The type of project requests received by eG4C demonstrated that the following are typical WCG e-Government types of sites (D2):

Informational: The goal of this site is to provide information regarding a specific topic. Example: the WCG news and speeches page $\AA^{4}$.

Transactional: The goal of this site is for the user to complete a transaction, such as filling in a form. Example: the WCG online job application page 5 .

Campaign: The goal of this site is to promote a specific topic. A campaign can be informational and/or transactional. Example: the WCG Safely Home website 6

Social media: The goal is to have a social media presence in order to interact with citizens. Example: the $110 \%$ Green Facebook pag $\rrbracket^{7}$.

\footnotetext{
${ }^{4}$ http://www. westerncape.gov.za/news

${ }^{5}$ http://www.westerncape.gov.za/jobs/how-to-apply

${ }^{6}$ http://safelyhome.westerncape.gov.za

${ }^{7}$ https://www. facebook. com/110Green
}

In 2012, a project brief was created and institutionalised and served as a project proposal (D3). Any client had to complete the project brief in conjunction with the e-G4C team in order for work to be defined and conducted. The e-G4C project brief assisted in project planning (D4). The goal of project planning is to start with clear project approach and objectives. The WCG website Programme Manager together with a project manager plans a new project with e-G4C stakeholders after the completion of the project brief by a client.

The next step is to develop business requirements (D5). E-G4C did not have business analysts in the staff structure during this research study. The result of the lack of staff capacity was that business requirements are normally developed informally. In order to improve business requirements for e- $\mathrm{G} 4 \mathrm{C}$ projects, business analyst positions were added to the future e-G4C staff structure. Dedicated staff members will be developing business requirements in the long-term. Contract business analysts were used for selected projects.

User research (D6) is required to obtain knowledge about the intended users of a website. A UX process needs to consider user expectations and goals in order to design a website in a UX perspective. The user research methods included surveys, focus groups and Google Analytics. Pretorius [46] conducted user research in rural areas of the Western Cape in order to inform the website design of the WCG Cape Access website.

Once user research has been conducted, the site can be designed (D7). Highlighted sub-steps include: implement a content strategy; identify user tasks; determine site structure and navigation; develop prototypes; collect user feedback; create the visual design; implement the corporate brand and evaluate the site. The recommended sub-steps [45] were included in the updated e-G4C SDLC (Phase E: E3).

Once a design is in place, development can commence (D8). The original Content Management System (CMS) on which the WCG website was built was still being used after almost ten years and was becoming unstable 47. The CMS enables government content-publishing teams to publish on the Web; however, in 2012, publishing and updating content on the CMS became difficult and time consuming. A decision was made to migrate to a new open source CMS, Drupal. Furthermore, e-G4C lacked developer capacity to move to the new Drupal CMS standard [47. A modern CMS and developer capacity are required in order to successfully develop a website. Migration to the new Drupal open source platform was completed in 2013.

Usability testing and heuristic evaluations were used to test the WCG e-Government website (D9). Phase E: E2 elaborates on a usability laboratory that was built for e-G4C. Usability studies at e-G4C are conducted using the usability and eye tracking methodology by Pretorius and Calitz [48. After the site has been designed, developed and tested it can be launched (accessible to the public). Before the launch of the site (D10), it is important to conduct the following ac- 
tivities: create social media accounts (if applicable); do cross-browser checks; proofread content; create a content plan; market the launch; plan after-launch tasks and check technical details. A highlighted result included the creation of a Twitter account for the $\mathrm{WCG}^{8}$ providing WCG news and information and links back to the WCG e-Government website. Social media policy, strategy and implementation guidelines are required for social media accounts and were developed for the WCG in 2012. Additionally, cross-browser checks were sporadic in the WCG before the start of this study. Cross-browser checks were implemented for the WCG e-Government website and were included in the updated SDLC.

Finally, support needs to be delivered after the launch (D11). Sub-steps for this activity include: implement change management; conduct user training; provide customer support; determine the impact on the organisation and stakeholders; collect analytics and work through iterations. These after launch support sub-steps were included in the updated e-G4C SDLC.

Phase D (method) of the IUXG methodology described the required steps to conduct a UX project. All steps of phase D, including designing, developing, testing and refining WCG websites were included in the updated SDLC, incorporating UCD.

\subsection{Phase E: standards}

The focus of the standards phase is to minimise rework, enforce consistency and to take advantage of what is already known about best practices. The steps for Phase E include:

- E1. Create templates;

- E2. Create a testing facility;

- E3. Standardise processes;

- E4. Compile best practices and guidelines.

The use of templates (E1) assists in effective completion of the method phase. After using the method for initial projects, templates start to formalise and standardise. The IUXG methodology recommended templates for documents and forms, as well as for interface design standards. The following documents and form templates were created:

- informed consent form,

- usability testing planning document,

- screening questionnaire,

- post-test questionnaire,

- usability results report,

- focus group planning document and report, and

- an online survey.

E-G4C initiated a project to build a usability laboratory (E2). Users are brought into a controlled environment, in which they are asked to do specific tasks within specific timeframes. Evaluators observe the problem(s) the participant might have, videotape the participant and then analyse the observational logs and videotapes. The construction plan for the usability laboratory is illustrated in Figure 4. The usability

\footnotetext{
${ }^{8}$ http://www.twitter.com/westerncapegov
}

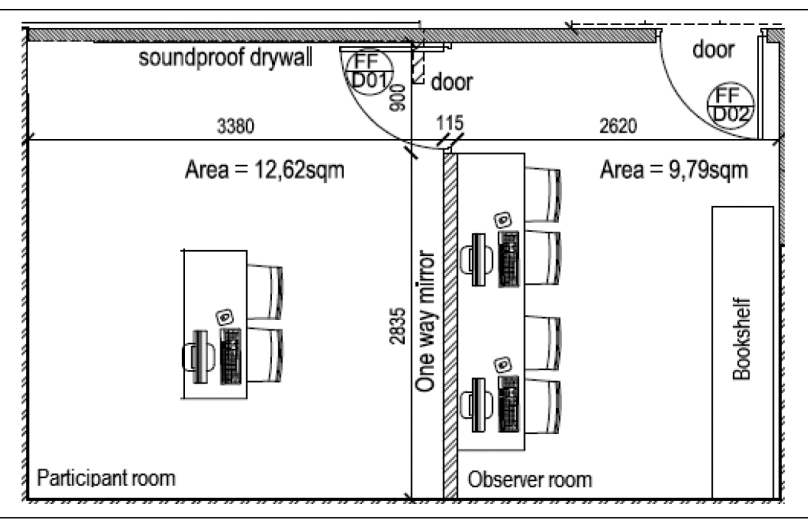

Figure 4: WCG Usability Laboratory construction plan

laboratory consists of two rooms, an observer room and a participant room divided by a one-way mirror. The usability laboratory was completed in 2012 and was the first usability laboratory for a SAPG. A dedicated usability testing facility shows a commitment to testing within the organisation [13.

The goal of step E3 was to standardise the UCD process in the SDLC. An internal investigation was completed to investigate if the SDLC adequately includes UX, applied through UCD. The findings concluded that UX and UCD were not adequately covered in the SDLC. The words "usability", "UX" or "UCD" were not mentioned in the SDLC document. A revised SDLC was proposed to senior management to include UCD [45. The proposed SDLC was reviewed by eG4C staff and the WCG Corporate Governance team. The proposed SDLC 45] was approved and signed off in 2014.

The final step of this phase is to compile UX best practices and guidelines (E4). During 2012, a first draft document of official WCG UX policy, strategy and guidelines was released 44]. This document provided a list of usability, design and UX guidelines to be applied to WCG websites and systems. Additionally, a list of UX resources was compiled listing the popular UX resources used by the UX team. The list consists of website links, books and Twitter users.

The standards phase (E) assisted in minimising rework, enforcing consistency and taking advantage of what is already known about best practices.

\subsection{Phase F: long-term}

The long-term phase focuses on the management and long-term considerations to keep UX institutionalised in government. The steps for Phase F include:

- F1. Maintain the management relationship;

- F2. Maintain UX awareness;

- F3. Collect metrics;

- F4. Adhere to laws and regulations;

- F5. Stay up to date with latest trends and research;

- F6. Measure UX maturity level.

A goal of the "maintain the management relationship" step (F1) is to maintain respect and momentum in the organisation. The UX team needs to maintain enough 
respect for users' needs to be fulfilled without being marginalised, ignored or overrun, because technology takes precedence over usability. This goal was achieved through continuous UX presentations to WCG senior management and by showcasing UX work conducted. Further, the work on the updated SDLC and the establishment of UX strategy, policy and guidelines kept management involved in UX projects.

Maintaining UX awareness (F2) should be an ongoing practice. UX was advocated as follows:

- UX presentations were conducted to staff and management to advocate the concepts of UX in e-G4C and the WCG;

- UX success stories and improvements were showcased;

- Sessions with departments were held to improve their presence on the WCG website;

- Findings from UX methods, such as focus groups and usability testing, were documented as official WCG documents.

It is important to collect metrics (F3) to demonstrate that the investment in UX is providing results. A Google Analytics account was created to track detailed statistics about the visits to the WCG website. The number of unique visitors increased from 1829930 in $2010 / 2011$ to 3019828 in 2011/2012.

When a government public website is developed, awareness of the laws, regulations, policies and other directives is essential (F4). For example, in the United States, laws exist regarding accessibility requirements. Currently, there is no current law or regulation in South Africa that addresses UX directly. The WCG is drafting a new WCG e-Government strategy [30], which will have an impact on the WCG e-Government website.

The goal of step F5 was to stay current with latest research, trends and best practices. A highlight of this step was that mobile was identified as a trend to take note of. The WCG launched its first mobile website in $2012^{9}$. This was the first mobile website developed by a SAPG. The site was designed for basic feature phones to promote digital inclusion. In 2014, another trend was realised, when the WCG developed its first fully responsive website 10

Responsive web design is a web development approach that creates dynamic changes to the appearance of a website, depending on the screen size and orientation of the device being used to view it 49 . Other identified trends include: social media; semantic Web; customer relationship management; transactional services; user generated content; application programming interface and open data; use of multimedia and open source. The WCG Portal is now on an open source platform, Drupal (as discussed in Section 4.4).

After all phases and steps of the IUXG methodology have been implemented, the UX maturity of the organisation needs to be measured again (F6) for improvements. As described in Phase A, the measured UX maturity level for the WCG at the start of this

\footnotetext{
${ }^{9}$ http://m.safelyhome.westerncape.gov.za/

${ }^{10}$ http://www. westerncape.gov.za/capeaccess/
}

study was (second survey): Schaffer, stage 4, Nielsen, level 2 and Feijo, level 1 [38. The measured UX maturity level for the WCG at the end of this study was (third survey): Nielsen, stage 6, systematic usability process; Shaffer, level 3, infrastructure and Feijo, level 3 , invested 38 . The UX maturity level improved on all three UX maturity models for the WCG. These results were gathered from the third survey with WCG employees as the participants.

Phase F (long-term) focused on the management and long-term considerations in order to keep UX institutionalised in government and is an on-going exercise. The research results of this study are discussed next.

\section{DISCUSSION}

The importance of UX in e-Government has been highlighted by several studies [2, [9]. A number of studies have listed guidelines that e-Government websites should satisfy for them to be a usable design [2, [9], [19], 20], 24. Despite the highlighted importance of UX, it is rarely adopted in South African e-Government websites [10]. The IUXG methodology was proposed to assist South African Provincial Governments (SAPGs) to establish UX practice as a norm: to institutionalise UX.

Phase A of the IUXG methodology, startup, identified the Schaffer [13, Nielsen [25] and Feijo 26] UX maturity models. The measured UX maturity level for the WCG before this study was (second survey): Nielsen, stage 4, dedicated usability budget; Schaffer, level 1, piecemeal usability and Feijo, level 2, interested. Phase F measured the success of the IUXG methodology in terms of the increase in the UX maturity levels achieved. The measured UX maturity level for the WCG after this study was (third survey): Nielsen, stage 6 , Shaffer, level 3 and Feijo, level 3 38. The survey results demonstrated that the implementation of IUXG Methodology increased the UX maturity of the WCG.

The IUXG methodology was successfully proposed and evaluated. The UX maturity model levels, as described above, were used as an admonition together with the usability results of the WCG website determined by focus group results. An executive champion and UX consultant created buy-in for UX in the WCG.

The setup phase (B) of the IUXG methodology delivered a UX policy, strategy and guidelines for the WCG. The goal of the WCG is to make the UX guidelines available to all SAPGs after it is formalised. UX methods were selected for the WCG, including user research (focus groups, surveys), designing a website or system (wireframes and templates, Web design) and usability testing of a website (heuristic evaluations, usability laboratory testing). These UX methods were incorporated into the SDLC process in order to accommodate UCD. A budget was successfully set up for the UX team of the WCG. UX skills and knowledge training were conducted in the WCG.

Phase C (organisation) of the IUXG methodology helped to develop the UX team. The UX team was 
established as a centralised UX structure. The UX team developed from one staff member in 2010 to five staff members in 2012.

Phase D (method) of the IUXG methodology described the required steps to conduct a UX project. An e-G4C project brief document was created that served as the project proposal for new projects and assisted with project planning. Surveys, focus groups and Google Analytics provided early, valuable user research. All steps of Phase D, including designing, developing, testing and refining WCG websites were included in the updated SDLC.

The standards phase (E) assisted in minimising rework, enforcing consistency and taking advantage of what is already known about best practices. Wireframe and design templates were created for the WCG website. The first usability laboratory for a SAPG was built. UX was successfully incorporated into the SDLC.

Phase F (long-term) focused on the management and long-term considerations in order to keep UX institutionalised in government. WCG management was continuously involved through UX presentations and as stakeholders in the UX policy, strategy and guidelines document and updated SDLC project to maintain the management relationship and UX awareness. Latest trends, including social media, mobile and responsive design were identified and are currently in progress in the WCG.

The research questions of this study were successfully addressed: a methodology could be proposed and evaluated to institutionalise UX in a South African Provincial Government. The implementation of the methodology further increased the UX maturity of a South African Provincial Government. The theoretical and practical contributions of this study are discussed next.

\section{CONTRIBUTIONS OF THE STUDY}

Several significant contributions have been made to the UX and e-Government fields, especially in relationship to South African provincial governmental websites. Additionally, the findings of the research can be applied and adopted by governments, specifically governments of emerging economies. The theoretical contributions of this study are discussed next.

Buie and Murray [50] published a book in 2012 entitled "Usability in Government Systems". The authors state that the publication is the first that concentrates on the role of usability in government systems. The research conducted in this study, contributes to usability studies in government systems and is the first research to propose and evaluate a methodology to institutionalise UX in a SAPG. Methodologies to institutionalise UX (ranging in detail) exist [13, 21, 40, 41, 42, however, these UX methodologies are not aimed specifically at SAPGs. The purpose of this research was to propose and evaluate a methodology to institutionalise UX in SAPGs, named the Institutionalise UX in Government (IUXG) methodology. The initial, pro- posed IUXG methodology was designed from five UX methodologies found in literature [13], 21], 40, 41, 42 , as well as best practices found in literature.

The IUXG methodology was updated, based on results of the survey to SAPGs, a survey to WCG employees, as well as literature from the WCG. The IUXG methodology was finally updated based on the case study results and on a confirmation survey with WCG employees after the implementation of the case study.

The research demonstrated that the UX maturity levels of SAPGs are low [10. An organisation with a low maturity rating is unlikely to be able to conceive of the processes necessary to bring about the highest levels of UX maturity [51. The advantage of the IUXG methodology is that it provides PG officials with a stepby-step method on how to institutionalise UX in a PG.

The six phases of the IUXG methodology, startup, setup, organisation, method, standards and long-term, will assist PG officials to obtain increased UX maturity levels, as was evaluated in the WCG case study. The IUXG methodology will empower PGs with the resources, methods and tools to be able to implement UX guidelines and will result in a more user-centric PG e-Government website.

The IUXG methodology was implemented in a SAPG environment (the WCG) and thus generated real-world results, making this study unique. Horton and Lazar state that there is often hesitation from universities to work with practitioners:

But the reality is, what could be better than actually influencing either practitioners in UX, or developers, or policy-makers? 52.

This study influenced all three role-players listed. The results of the case study will allow other Provincial Governments to observe the challenges and lessons learnt from this UX institutionalisation project.

This research study has made the following practical contributions in the WCG and e-G4C:

- UX methods, including focus groups, surveys, wireframes, Web design, templates, usability laboratory testing and heuristic evaluations are standard practice for the WCG e-Government website [4];

- UCD is part of the SDLC used by e-G4C for the WCG e-Government website [45];

- The SDLC used by e-G4C has been proposed for the wider WCG (to be used for systems, not part of the e-Government website) 45. UX activities were included in the overall WCG SDLC in 2014 53 ;

- A UX policy, strategy and guidelines document 44. has been recommended and was approved by WCG senior management members. The document will apply to the WCG e-Government website and other WCG websites and systems. The concept of UX together with the UX policy and guidelines were presented to the Premier of the Western Cape. The Premier welcomed these resources and indicated that she is looking forward to the impact that UX can make in the WCG [54]; 
- The IUXG methodology was presented at a South African National Government level at the Government Information Technology Officers Council (May 2013). The Council requested that the developed UX guidelines be shared with all South African Government institutions. The WCG UX team is currently developing a UX Toolkit website that will be shared with South African Government institutions. The UX Toolkit website will include UX guidelines, as well as wireframe and design templates;

- The UX maturity level of the WCG was measured three times throughout this research study. The WCG has improved on all identified UX maturity models due to the implementation of the IUXG methodology;

- Base templates for wireframes, design and usability testing projects were created;

- The first author of this research was the only UX employee at the start of this research study. The WCG UX team consisted of five staff members at the conclusion of this research study;

- Improvements to the WCG e-Government website were made (Figure 1; initial in 2010; Figure 5 after in 2012) through recommendations from focus groups, usability testing and heuristic evaluations and by applying UX methods such as wireframing and Web design;

- The result of UX, content and technical improvements were that an increased number of citizens used the WCG e-Government website. The number of unique visitors increased from 1829930 in 2010/2011 to 3019828 in 2011/2012;

- A usability testing facility was constructed and is the first usability testing facility for a SAPG.

\section{CONCLUSION}

Straub and Gerrol [7] indicate that "Putting government online is one thing; making government websites functional and easy to use is quite another". Users interacting with government websites often experience that not enough has been done to anticipate their needs or make information easily available and locatable [7. The user experience with government websites does not compare well with the online experiences that citizens have in the private sector. Citizens' higher perception of the usefulness and ease of use of e-Government websites directly enhanced the level of intention of citizens to continue to use e-Government websites [5].

The need for this research was based on the premise that UX processes are not mature and institutionalised in SAPGs 10. The importance of UX in government has grown and is considered a best practice in countries such as the United States 21. UX does not appear to be a best practice or a standard in the South African Government. Although there is a substantial body of UX knowledge, the information is generally only practised by specialists in the field. There is a lack of understanding and buy-in of UX at PG level. The

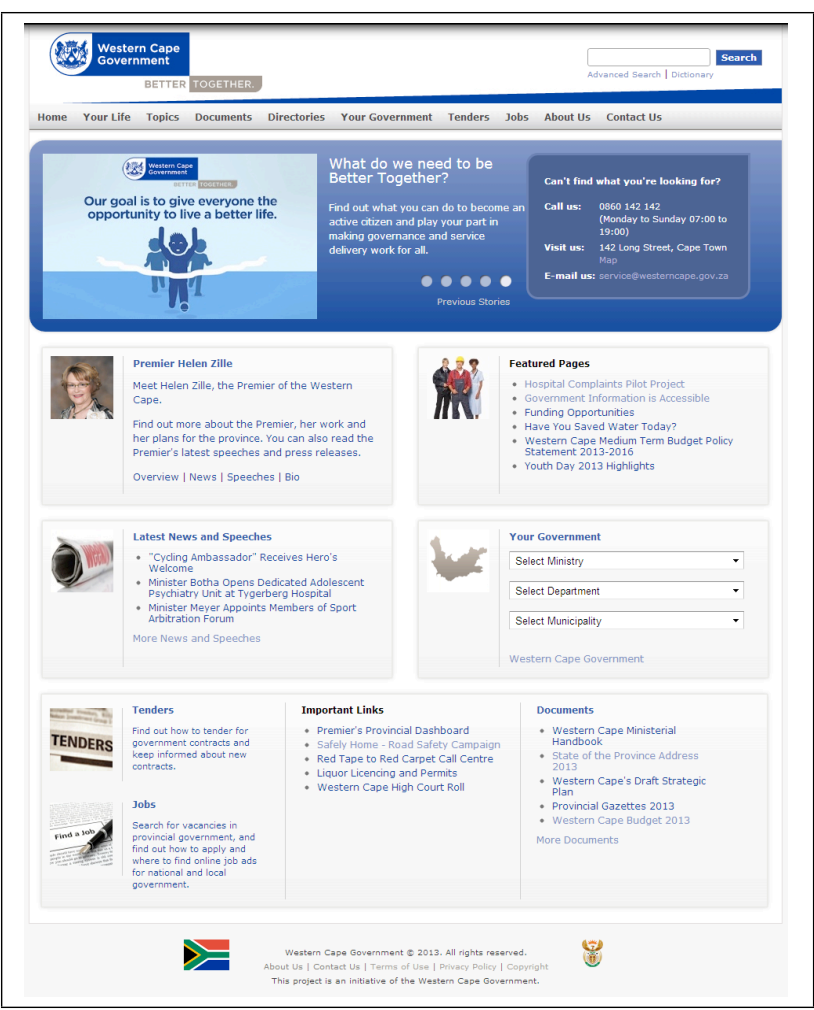

Figure 5: Western Cape Government website after this study (June 2013)

institutionalisation of UX is important if an organisation has to move from an ad hoc UCD approach to a sustained and managed UX practice [55].

This study provided a methodology on how to institutionalise UX in a SAPG, named the Institutionalise User Experience in Government (IUXG) methodology. The results of the implementation of the IUXG methodology, as a case study in the WCG, resulted in: an improved UX maturity level; UX activities became standard in the e-Government website environment; the SDLC was updated to incorporate UCD and became standard; UX policy, strategy and guidelines were documented; the first usability testing facility for a SAPG was built; improvements to the WCG e-Government website were implemented; and the number of visits to the WCG website improved. The IUXG methodology institutionalised UX in the WCG e-Government website environment. If Provincial Governments implement this methodology, their organisation will be more user-centric, they will be able to focus on the user experience and they will be able to implement existing UX guidelines.

Additionally, the surveys conducted at the start and end of the implementation of the IUXG methodology, showed that the UX maturity of the SAPG (used in the case study), improved. The implementation of the IUXG methodology by other SAPGs will improve their UX maturity.

Future research includes the application of the IUXG methodology to other Provincial Governments in South Africa. Additionally, the application of the IUXG methodology to South African local and national government levels, as well as to international emerging economy governments, is identified as future research. 
The IUXG methodology can be adapted to be applicable in non-government areas such as the banking and e-Commerce industries. The customisation of the IUXG methodology to other industry sectors is identified as future research. Future research also includes the customisation of the IUXG methodology to other areas of an organisation, such as walk-in centres and contact channels. The full IUXG methodology by Pretorius 38] can be accessed at www.uxstrategy.co.za.

\section{RESEARCHER INVOLVEMENT}

The researcher of a study is typically an "outside researcher" or an "involved researcher" 56. "Outside researchers" typically carry out studies using formal interviews without any involvement in the field [56]. An "involved researcher" is seen as a participant observer or is involved in the field of activity [56]. The researcher's involvement in this study was that of an "involved researcher". The researcher was the leader of the UX team at the WCG and it was his responsibility to institutionalise UX in the PG.

An advantage of an involved researcher is the indepth access to people, issues and data [56]. An involved researcher has the opportunity to observe and participate at first hand, rather than merely accessing opinions as is the case in an interview-only study. The researcher, as the UX manager, had a mandate to institutionalise UX in the WCG to allow direct access to people, issues and data. Certain positive benefits can often be gained, because the field participants see the researcher attempting to make a valid contribution to the field site itself, rather than merely taking the data away and writing it up solely for the literature. There is a frequent call for IS researchers to make their work more relevant in practice [56, 57.

A disadvantage of involved research is that it is time-consuming [56]. This constraint allowed for only a single case study to be explored. Close involvement may not always be possible as this may not be allowed by the organisation [56. The WCG allowed close involvement and provided permission for the study and for the results to be published.

Close involvement may also cause participants to be less open and honest with the researcher in cases where he or she is perceived to have a vested interest. The potential problem is addressed as the author of this research was not in a position of power. The participants of the first survey included government officials from the nine South African PGs; the author has no position of power over these participants. Additionally, the WCG officials participating in the follow-up surveys consist of peers and a manager of the author. The WCG officials are also consulted in the case study results.

Additionally, a danger exists that the closely involved field researcher becomes socialised to the views of the people in the field and loses the benefit of a fresh outlook on the situation [56. This potential problem is avoided by documenting the case study results through official procedures and professional protocols in the
WCG.

\section{ACKNOWLEDGMENTS}

E-Government for Citizens in the Department of the Premier of the Western Cape Government is thanked for their support to make this research possible. Clayton Wakeford, Director of e-Government for Citizens, is specifically thanked for his support of this research.

\section{REFERENCES}

[1] J. Kuzma. "Asian government usage of Web 2.0 social media". European Journal of ePractice, , no. 9, March 2010. URL http://www.epractice.eu/en/document/ 313346 .

[2] A. Yeratziotis. The impact of cultural context on web design for e-government in South Africa. Master's thesis, Nelson Mandela Metropolitan University, 2008.

[3] B. Bailey. "User-friendly web sites keep agencies in touch with citizens", 2002. URL http:// www . humanf actors . com/news/coverage . asp. Last accessed 23 September 2013.

[4] H. S. Al-Khalifa. "Heuristic evaluation of the usability of e-government websites: a case from Saudi Arabia". In Proceedings of the 4th International Conference on Theory and Practice of Electronic Governance, pp. 238-242. ACM, 2010.

[5] S. Wangpipatwong, W. Chutimaskul and B. Papastratorn. "Understanding citizens continuance intention to use e-government website: A composite view of technology acceptance model and computer self-efficacy". The Electronic Journal of e-Government, vol. 6, no. 1, pp. 55-64, 2008.

[6] M. Chango. "Challenges to e-government in Africa south of Sahara: a critical view, and provisional notes for a research agenda". In Proceedings of the 1st international conference on Theory and practice of electronic governance, pp. 384-393. ACM, 2007.

[7] K. Straub and S. Gerrol. "Designing the e-government experience through citizen-centred usability". White paper, 2008. URL http://www.humanfactors.com/ downloads/documents/eGovernment.pdf

[8] B. Soufi and M. Maguire. "Achieving usability within e-government websites illustrated by a case study evaluation". In Proceedings of the 2007 conference on human interface: Part II, pp. 777-784. Berlin, Heidelburg: Springer-Verlag, 2007.

[9] H. Korsten and T. J. D. Bothma. "Evaluating South African government Web sites: methods, findings and recommendations (Part 2)". South African Journal of Information Management, vol. 7, no. 3, 2005.

[10] M. Pretorius and A. Calitz. "The South African user experience maturity status for website design in provincial governments". In Proceedings of the 12th European Conference on eGovernment, 14-15 June 2012, Institute of Public Governance and Management ESADE, Barcelona, Campus Sant Cugat, Barcelona, Spain, pp. 589-599. 2012.

[11] E. Schaffer. "Institutionalization of usability". Video, 2012. URL http://www . youtube.com/watch? $\mathrm{v}=\mathrm{aUX3krFIivs}$. Last accessed 17 November 2014. 
[12] n.a. "Institutionalization: Oxford Dictionaries", n.d. URL http://www.oxforddictionaries.com/ definition/english/institutionalize. Last accessed 17 November 2014.

[13] E. Schaffer. Institutionalization of usability: A stepby-step guide. Boston, MA: Addison-Wesley, 2004.

[14] E. N. Asiimwe and N. Lim. "Usability of government websites in Uganda". Electronic Journal of e-Government, vol. 8, no. 1, pp. 1-12, 2010.

[15] D. Pilling and H. Boeltzig. "Moving toward egovernment: effective strategies for increasing access and use of the internet among non-internet users in the US and UK". In Proceedings of the 8th annual international conference on Digital government research: bridging disciplines $\& 5$ domains, pp. 35-46. Digital Government Society of North America, 2007.

[16] J. Nielsen and H. Loranger. Prioritizing web usability. Berkeley, CA: New Riders, 2006.

[17] "ISO 9241-210. Ergonomics of Human-System Interaction part 210: Human-centred design for interactive systems".

[18] Z. Huang. Usability and credibility evaluation of electronic governments: Users perspective. Ph.D. thesis, School of Information Systems, Computing and Mathematics, Brunel University, 2010.

[19] B. M. AlFawwaz. Evaluation of eGovernment websites usability in Jordan. Ph.D. thesis, Brunel University, 2012 .

[20] J. Mifsud. "Official usability and web site guideguide of governments from around the world", 2011. URL http://usabilitygeek.com/official-usabilityweb-site-guidelines-of-governments-fromaround-the-world Last accessed 17 November 2014.

[21] n.a. "Usability.gov: Improving the user experience", 2012. URL http://www.usability.gov. Last accessed 17 November 2014.

[22] UK Government. "Accessibility", 2014. URL https: //www.gov.uk/help/accessibility. Last accessed 17 November 2014.

[23] J. Vermeulen. "Disappointing high-profile websites: Really, we can do better", 2010. URL http://mybroadband.co.za/news/columns/16905Disappointing-high-profile-websites-Reallycan-better.html. Last accessed 17 November 2014.

[24] R. Matavire, W. Chigona, D. Roode, E. Sewchurran, Z. Davids, A. Mukudu and C. Boamah-Abu. "Challenges of eGovernment project implementation in a South African context". The Electronic Journal Information Systems Evaluation, vol. 13, no. 2, pp. 153-164, 2010.

[25] J. Nielsen. "Corporate UX maturity: Stages 14", April 2006. URL http://www.nngroup.com/ articles/usability-maturity-stages-1-4/, Last accessed 17 November 2014.

[26] R. Feijo. "Planning your UX strategy", April 2010. URL http://johnnyholland.org/2010/04/ planning-your-ux-strategy/ Last accessed 17 November 2014.

[27] K. Straub, M. Patel, A. Bublitz and J. Broch. "The HFI UX maturity survey 2009: Findings". White paper, 2009. URL http://www.slideshare.net/kstraub/hfi- usability-practice-maturity-model Last accessed 17 November 2014.

[28] M. Ide-Smith. "Winning hearts and minds: How to embed UX from scratch in a large organisation", 2011. URL http://www.slideshare.net/ micheleidesmith/winning-hearts-and-mindsembedding-ux-in-a-large-organisation. Last accessed 17 November 2014.

[29] M. Blessing and N. Klaas. "Crafting an e-government development model for South Africa: A strategic new direction for the Western Cape province". In CONFIRM 2009 Proceedings. 2009. URL http://aisel. aisnet.org/confirm2009/7/

[30] Western Cape Government. "e-Government strategy: 2012-2019, Version 1.0", 2012. URL http://www . westerncape.gov.za/text/2012/10/ wcg-draft-e-government-strategy-for-publiccomment-october-2012.pdf Last accessed 17 November 2014.

[31] Western Cape Government. "Western Cape Government", 2014. URL http://www . westerncape.gov.za Last accessed 17 November 2014.

[32] M. Saunders, P. Lewis and A. Thornhill. Research methods for business students. Harlow: Prentice Hall, 5th ed edn., 2009.

[33] R. Yin. "Case study methods". In J. Green, G. Camilli and P. Elmore (editors), Handbook of complementary methods in education research. Mahwah, NJ: Lawrence Erlbuam Associates, 2006.

[34] I. Benbasat, D. K. Goldstein and M. Mead. "The case research strategy in studies of information systems". MIS quarterly, pp. 369-386, 1987.

[35] C. Robson. Real world research. Oxford: Blackwell, 2nd ed edn., 2002.

[36] J. Lazar, H. Feng and H. Hochheiser. Research methods in human-computer interaction. New York: John Wiley \& Sons, 2010.

[37] E. Hofstee. Constructing a good dissertation: A practical guide to finishing a master's, MBA or PhD on schedule. Johannesburg: EPE, 2006.

[38] M. Pretorius. A methodology to institutionalise user experience in a South African provincial government. Ph.D. thesis, Nelson Mandela Metropolitan University, 2012.

[39] L. Rea and R. Parker. Designing and conducting survey research: A comprehensive guide. San Francisco, CA: Jossey-Bass, 3rd ed edn., 2005.

[40] ISO. "ISO TR 18529: Ergonomics of human system interaction. Human-centred lifecycle process descriptions". Tech. rep., ISO, 2000.

[41] HIMSS Usability Task Force. "Promoting usability in health organizations: Initial steps and progress toward a healthcare usability maturity model". Health Information and Management Systems Society, 2011. URL http: //www.himss.org/files/HIMSSorg/content/files/ HIMSS_Promoting_Usability_in_Health_Org.pdf. Last accessed 17 November 2014.

[42] R. Unger and C. Chandler. A project guide to UX design: For user experience desdesign in the field or in the making. Berkeley, CA: New Riders, 2009. 
[43] M. Pretorius and A. Calitz. "The use of focus groups to improve an e-Government website". In The 3rd Symposium of Web Society, 26-28 October 2011, Port Elizabeth, South Africa. 2011.

[44] M. Pretorius. Usability and design: Policy, strategy and guidelines. Version 0.3. Western Cape Government, 2012.

[45] M. Pretorius. e-Government for citizens: Systems development lifecycle. Version 0.7. Western Cape Government, 2012.

[46] M. Pretorius. "Focus on the citizen: User research in the rural areas of the Western Cape". In Annual Conference of the South African Institute of Computer Scientists and Information Technologists (SAICSIT) 30 Sep-1 Oct 2014, East London, South Africa. 2014.

[47] A. Levy. "Planning the Western Cape Government mobile website", May 2012. URL http://aslamlevy.co.za/2012/05/planningthe-western-cape-government-mobile-website. Last accessed 17 November 2014.

[48] M. Pretorius and A. Calitz. "The development of a usability methodology incorporating eye tracking for developing countries". In Fourth International Business Conference, 12-14 October 2010, Victoria Falls, Zambia. 2010.

[49] A. Schade. "Responsive web design (RWD) and user experience", 2014. URL http://www.nngroup.com/ articles/responsive-web-design-definition Last accessed 17 November 2014.

[50] E. Buie and D. Murray. Usability in government systems: User experience design for citizens and public servants. Amsterdam: Elsevier, 2012.

[51] J. Earthy. "Usability Maturity Model: human centredness scale". INUSE Project deliverable D, vol. 5, 1998.

[52] S. Horton and J. Lazar. "Accessibility research methods", 2014. URL http://www . uie.com/brainsparks/ 2014/05/09/sarah-horton-and-jonathan-lazaraccessibility-research-methods/ Last accessed 17 November 2014.

[53] T. Kunene. Western Cape government systems development lifecycle framework. Western Cape Government, 2014.

[54] Western Cape Government. "The Western Cape government usability lab". Better Together Magazine, June/July 2013.

[55] "How to support the institutionalisation of a mature UX practice", 2012. URL http://www . humanfactors com/training/institutionalization.asp. Last accessed 17 November 2014.

[56] G. Walsham. "Doing interpretive research". European Journal of Information Systems, vol. 15, pp. 320-330, 2006.

[57] R. Baskerville and M. D. Myers. "Special Issue on action research in Informaton Systems: Making IS research relevant to practice foreword". Management Information Systems Quarterly, vol. 28, no. 3, p. 2, 2004. 